\title{
Identification of missense mutations in the hepatocyte nuclear factor-3 $\beta$ gene in Japanese subjects with late-onset Type II diabetes mellitus
}

\author{
Q.Zhu ${ }^{1}$, K. Yamagata ${ }^{1}$, L. Yu ${ }^{2}$, H.Tomura ${ }^{3}$, S. Yamada ${ }^{3}$, Q. Yang $^{1}$, I. Yoshiuchi ${ }^{1}$, S.Sumi ${ }^{4}$, J.Miyagawa ${ }^{1}$, J.Takeda $^{3}$, \\ T.Hanafusa ${ }^{1}$, Y.Matsuzawa ${ }^{1}$ \\ ${ }^{1}$ The Department of Internal Medicine and Molecular Science, Graduate School of Medicine, Osaka University, Osaka, Japan, \\ ${ }^{2}$ Department of Metabolism and Clinical Nutrition, Graduate School of Medicine, Kyoto University, Kyoto, Japan \\ ${ }^{3}$ The Laboratory of Molecular Genetics, Department of Cell Biology, Institute for Molecular and Cellular Regulation, \\ Gunma University, Maebashi, Gunma, Japan \\ ${ }^{4}$ Suita Municipal Hospital, Suita, Osaka, Japan
}

\section{Abstract}

Aims/hypothesis. Hepatocyte nuclear factor (HNF)$3 \beta$, a transcription factor expressed in pancreatic beta cells, is an upstream regulator of $H N F-1 \alpha /$ MODY3, HNF-4a/MODY1 and IPF1/MODY5 genes. Our previous screening of MODY subjects showed that mutations in the $H N F-3 \beta$ gene are not a common cause of this form of diabetes in the Japanese. We tested the hypothesis that mutations in the $H N F-3 \beta$ gene cause late-onset Type II (non-insulindependent) diabetes mellitus in this population.

Methods. Genotyping of the polymorphic TCC repeat in the $H N F-3 \beta$ gene was done in 112 Japanese subjects with Type II diabetes (age at diagnosis $>35$ and family history of Type II diabetes among their second-degree relatives) and 96 Japanese control subjects. Furthermore, we screened 57 Type II diabetic patients for mutations of the $H N F-3 \beta$ gene.
Transactivation activity of variant HNF-3 $\beta$ was investigated by transfection assay.

Results. The distribution of alleles of the TCC repeat was similar between diabetic and control groups. $\mathrm{Mu}-$ tation screening identified two missense mutations, A86T and G114E. Neither mutation was observed in 225 control subjects. The transactivation activity of G114E-HNF-3 $\beta$ was similar to that of wild typeHNF-3 $\beta$. In contrast, the activity of A86T-HNF-3 $\beta$ was statistically significantly reduced to $83-86 \%$ of that of wild type.

Conclusions/Interpretation. The A86T mutation in the $H N F-3 \beta$ gene might be involved in the development of late-onset Type II diabetes in a small group of Japanese people. [Diabetologia (2000) 43: 11971200]

Keywords Keywords. HNF-3 $\beta$, HNF- $1 \alpha$, mutation, genetics.
Maturity-onset diabetes of the young (MODY) is an autosomal dominant form of early-onset Type II (non-insulin-dependent) diabetes mellitus. Recent genetic studies found that mutations in the genes encoding hepatocyte nuclear factor (HNF)-1 $\alpha$, HNF$1 \beta, \mathrm{HNF}-4 \alpha$ and insulin promoter factor-1 (IPF-1)

Received: 27 March 2000 and in revised form: 27 April 2000

Corresponding author: K. Yamagata, Department of Internal Medicine and Molecular Science, Graduate School of Medicine, B5, Osaka University, 2-2 Yamada-oka, Suita, Osaka, 565-0871 Japan

Abbreviations: MODY, Maturity-onset diabetes of the young; HNF, hepatocyte nuclear factor; IPF1, insulin promoter factor-1; WT, wild type; TTR, transthyretin. are causes of MODY3, MODY5, MODY1 and MODY4, respectively [1-3]. Hepatocyte nuclear factor $-1 \alpha, \mathrm{HNF}-1 \beta$ and HNF- $4 \alpha$ are functionally related transcription factors which are important for the pancreatic beta-cell functions. Insulin promoter factor -1 regulates the expression of the insulin and glucokinase/MODY2 genes. These findings suggest that the transcription factors expressed in beta cells are important. Hepatocyte nuclear factor $-3 \beta$ is a transcription factor containing a winged-helix DNA binding domain and is involved in the regulation of the expression of $H N F-1 \alpha / \mathrm{MODY} 3, H N F-4 \alpha / \mathrm{MODY} 1$ and IPF-1/MODY5 genes $[4,5]$. This raises the possibility that mutations in the $H N F-3 \beta$ gene cause a decrease in the synthesis of these transcription factors and lead to diabetes. We recently cloned cDNA and the 
gene encoding human HNF-3 $\beta$ [6]. Mutation screening in 45 Japanese subjects with MODY showed that mutations in the $H N F-3 \beta$ gene are not associated with MODY in the Japanese [6]. Linkage studies for common Type II diabetes susceptible loci in a large sample of affected sib-pairs in Finnish families have, however, identified a linkage peak around the $H N F$ $3 \beta$ gene on chromosome 20 [7]. In this study, we examined whether mutations in the $H N F-3 \beta$ gene are involved in the pathogenesis of late-onset Type II diabetes in Japanese subjects.

\section{Subjects and methods}

Subjects and screening of the HNF-3 $\beta$ gene. In this study, we studied unrelated Japanese subjects who had been diagnosed with Type II diabetes after 35 years of age and had a family history of Type II diabetes among their second-degree relatives. We tested 112 unrelated Japanese subjects with Type II diabetes and 96 unrelated Japanese control subjects for genotyping using a polymorphic TCC repeat in the intron 1. Polymerase chain reaction was carried out as described previously using a kit of TaKaRa LATaq with GC buffer (TaKa$\mathrm{Ra}$, Tokyo, Japan) and 6-carboxy fluorescein labelled primers (5'-CTATATCACCAGCCTCCCACGTCAC-3' and 5'GTTTCTTCTGAGGTTGGCAGTGCCGAGCTG-3') [6]. The PCR products were analysed with ABI Prism 377 DNA Sequencer and ABI Prism GeneScan Analysis Software (version 2.1) (PE Applied Biosystems, Foster City, Calif., USA). GeneScan-400HD ROX (PE Applied Biosystems) was used as a size control.

We did DNA sequencing of the coding regions and flanking introns of the HNF-3 $\beta$ gene [6] in 57 unrelated Japanese Type II diabetic patients. The occurrence of A86T (loss of NarI site) and G114E (gain of XhoI site) mutations in 225 control subjects were determined by PCR-restriction fragment length polymorphism (RFLP) and DNA sequencing. Written informed consents were obtained from all of the participants and the study was carried out in accordance with the Declaration of Helsinki as revised in 1996.

Construction of plasmids and reporter gene assay. Human HNF-3 $\beta$ cDNA was subcloned into pcDNA3.1 (Invitrogen, Carlsbad, Calif., USA). We introduced A86T and G114E mutations by in vitro mutagenesis. Three copies of the HNF-3 $\beta$ binding site of the mouse transthyretin (TTR) promoter were inserted upstream of the HSV-TK promoter/luciferase fusion gene (pHNF3 $\beta$-tk-Luc). Reporter constructs with HNF-1 $\alpha$ promoter (HNF-1 $\alpha$-pGL3) and TTR promoter (TTR-pGL3) have been described previously [8]. We transfected HeLa cells $\left(1.5 \times 10^{5}\right.$ cells/well $)$ with $100 \mathrm{ng}$ of HNF- $3 \beta$ expression and $500 \mathrm{ng}$ of reporter vectors together with $10 \mathrm{ng}$ of pRL-SV40 (Promega, Madison, Wis., USA) as an internal control using the LIPOFECTAMINE PLUS Reagent (Life Technologies, Rockville, Md., USA). The transactivation activity of wildtype (WT)-HNF-3 $\beta$, A86T-HNF-3 $\beta$ and G114E-HNF-3 $\beta$ was measured after $48 \mathrm{~h}$ using the Dual Luciferase Reporter Assay System (Promega). Renilla luciferase activity was used to normalize transfection efficiencies among experiments. Each experiment was repeated six times.

Statistical analysis. The statistical significance of the differences was assessed using the unpaired-Student's $t$ test. We considered $p$ less than 0.05 as significant.

\section{Results}

Genotyping of the TCC repeat. We observed ten different alleles (Table 1). The distribution of the alleles was similar between diabetic and control groups, indicating that this $H N F-3 \beta$ polymorphism is not associated with late-onset Type II diabetes in Japanese subjects.

Identification of variants in HNF-3 $\beta$ gene. Screening of the $H N F-3 \beta$ gene for mutations in 57 Japanese Type II diabetic patients with family histories of diabetes identified two missense mutations (A86T ( $\underline{G C C}$ to $\underline{A C C}$ ) and G114E (GGG to G $\underline{A G})$ ), two silent mutations in the codons for Ala97 (GCC to GCT) and Gly279 (GGA to GGG)) and one in the 3' untranslated region $(\mathrm{C} / \mathrm{T} ;+49 \overline{\mathrm{nt}}$ after stop codon). The existence of missense mutations was confirmed by the sequencing of the subcloned PCR products. The A86T mutation was identified in two unrelated subjects with Type II diabetes and this mutation alters an amino acid that is located in the transcriptional activation domain (region V) [9]. The other missense mutation G114E is located in the linker region between the transcriptional activation domain and DNA binding domain. Neither mutation was found in 225 Japanese control subjects. To assess whether A86T and G114E are common mutations in Japanese subjects with late-onset Type II diabetes, we studied more diabetic patients. The A86T and G114E mutations were not observed in the 175 and 95 subjects, respectively. Thus, frequencies of A86T and G114E in Japanese subjects with late-onset Type II diabetes were $0.8 \%(2 / 232)$ and $0.6 \%$ (1/152), respectively. These data suggest that neither mutation is a common cause of late-onset Type II diabetes in this cohort. The frequencies of the three other silent mutations were similar between diabetic and control groups (Table 2).

Clinical profiles of subjects with HNF-3 $\beta$ mutation. We identified the A86T mutation in two unrelated subjects with Type II diabetes. Subject 1 is a 54-year-

Table 1. Allele distribution of the polymorphic TCC repeat in the $H N F-3 \beta$ gene

\begin{tabular}{lccccc}
\hline $\begin{array}{l}\text { Allele } \\
\text { size (bp) }\end{array}$ & \multicolumn{2}{l}{ Type II diabetes $(n=112)$} & & \multicolumn{2}{c}{ Control subjects $(n=96)$} \\
\cline { 5 - 6 } & Number & $\begin{array}{c}\text { Frequency } \\
(\%)\end{array}$ & & Number & $\begin{array}{l}\text { Frequency } \\
(\%)\end{array}$ \\
\hline 170 & 1 & 0.40 & & 0 & 0.00 \\
193 & 0 & 0.00 & & 1 & 0.52 \\
208 & 12 & 5.36 & & 9 & 4.69 \\
211 & 5 & 2.23 & & 3 & 1.56 \\
214 & 17 & 7.59 & & 13 & 6.77 \\
217 & 127 & 56.25 & & 119 & 61.98 \\
220 & 1 & 0.40 & & 4 & 2.08 \\
223 & 41 & 18.33 & & 24 & 12.50 \\
226 & 16 & 7.14 & & 18 & 9.38 \\
229 & 4 & 1.79 & & 1 & 0.52 \\
\hline
\end{tabular}


Table 2. Mutations/polymorphisms in the $H N F-3 \beta$ gene

\begin{tabular}{|c|c|c|c|c|c|c|}
\hline \multirow[t]{2}{*}{ Region } & & \multirow{2}{*}{$\begin{array}{l}\text { Nucleotide } \\
\text { change }\end{array}$} & \multirow[t]{2}{*}{ Amino acid change } & & \multicolumn{2}{|l|}{ Allelic frequency } \\
\hline & & & & & $\begin{array}{l}\text { Type II diabetes } \\
(n=57)\end{array}$ & $\begin{array}{l}\text { Control } \\
(n=64)\end{array}$ \\
\hline \multirow{3}{*}{ Exon 3} & codon 97 & $\mathrm{C}$ to $\mathrm{T}$ & Ala (GCC) to Ala (GCT) & $\mathrm{C} / \mathrm{T}$ & $0.87 / 0.13$ & $0.77 / 0.23$ \\
\hline & codon 114 & $\mathrm{G}$ to $\mathrm{A}$ & Gly (GGG) to Glu (GAG) & $\mathrm{G} / \mathrm{A}$ & $0.99 / 0.01$ & $1.00 / 0.00$ \\
\hline & codon 279 & A to $\mathrm{G}$ & Gly (GGA) to Gly (GGG) & $\mathrm{A} / \mathrm{G}$ & $0.85 / 0.15$ & $0.77 / 0.23$ \\
\hline \multicolumn{2}{|c|}{$+49 \mathrm{nt}$ after stop codon } & $\mathrm{C}$ to $\mathrm{T}$ & & $\mathrm{C} / \mathrm{T}$ & $0.89 / 0.11$ & $0.77 / 0.23$ \\
\hline
\end{tabular}

Allele frequencies in the control subjects are cited from reference [6]

Table 3. Clinical characteristics of the diabetic patients with mutations in the $H N F-3 \beta$ gene

\begin{tabular}{|c|c|c|c|}
\hline & Subject 1 & Subject 2 & Subject 3 \\
\hline Mutation & A86T & A86T & G114E \\
\hline Age at diagnosis (years) & 44 & 38 & 65 \\
\hline $\begin{array}{l}\text { Duration of diabetes } \\
\text { (years) }\end{array}$ & 10 & 34 & 7 \\
\hline Present BMI $\left(\mathrm{kg} / \mathrm{m}^{2}\right)$ & 26.8 & 17.4 & 20.2 \\
\hline Present $\mathrm{HbA}_{1 \mathrm{c}}(\%)$ & 10.8 & 8.2 & 7.5 \\
\hline Therapy & Insulin & Insulin & OHA \\
\hline Complication & $\begin{array}{l}\text { PDR, } \\
\text { neuropathy } \\
\text { and nephro- } \\
\text { pathy }\end{array}$ & Neuropathy & Retinopathy \\
\hline
\end{tabular}

$\overline{\text { OHA, oral hypoglycaemic agent; PDR, proliferative diabetic }}$ retinopathy

old woman $(\mathrm{BMI}=26.8)$. She developed Type II diabetes at 44 years of age. She was first treated with an oral hypoglycaemic agent, and with insulin after she was 46 years of age. Her present $\mathrm{HbA}_{1 \mathrm{c}}$ value is $10.8 \%$ and she has proliferative diabetic retinopathy, diabetic nephropathy and severe neuropathy. Her present urinary $\mathrm{C}$ peptide is $28.2 \mu \mathrm{g} /$ day (normal range, 45 to $117 \mu \mathrm{g} / \mathrm{day})$. Her $\mathrm{C}$-peptide response to glucagon is impaired $(\Delta \mathrm{C}$-peptide $=0.46 \mathrm{nmol} / 1$ per $5 \mathrm{~min}$, normal $1.75 \pm 0.32$ ). The proband has six more siblings. Of them three developed late-onset Type II diabetes and have the A86T mutation. Out of six children of the proband's 64-year-old sister, who has the mutation and developed Type II diabetes at 53 years of age, three (present age; 37, 33 and 31 years of age) have inherited the mutant allele. One of the children (33-year-old woman), who also has the mutation, was identified as having glycosuria when she was pregnant at 24 years of age. The other children were not diabetic when interviewed, although glucose tolerance tests have not been carried out on these subjects.

Subject 2 is a 72 -year-old man $(\mathrm{BMI}=17.4)$. He developed Type II diabetes at 38 years of age and started insulin treatment 17 years after diagnosis. His present $\mathrm{HbA}_{1 \mathrm{c}}$ value is $8.2 \%$ and he has severe neuropathy. His children ( 38 and 42 years of age) were not diabetic when interviewed.
The proband with the G114E mutation is a 72year-old woman $(B M I=20.2)$. She developed Type II diabetes at 65 years of age. She is now being treated with an oral hypoglycaemic agent and her present $\mathrm{HbA}_{1 \mathrm{c}}$ is $7.5 \%$. She has two diabetic sisters, one of whom has the mutant allele.

Clinical data of subjects 1-3 are summarized in Table 3 .

Functional analysis of mutant $H N F-3 \beta$. We studied the functional properties of the mutant HNF- $3 \beta$ proteins. HeLa cells were transfected with WT and mutant HNF- $3 \beta$ constructs together with the pHNF- $3 \beta$ tk-Luc reporter. We found WT-HNF-3 $\beta$, A86THNF-3 $\beta$ and G114E-HNF-3 $\beta$ activated the reporter gene by 34 -fold, 28 -fold and 32-fold, respectively (Fig.1). The transactivation activity of A86T-HNF$3 \beta$ was significantly reduced to $83.4 \%$ of that of WT $(p=0.005)$ but the difference between WT-HNF-3 $\beta$ and G114E-HNF-3 $\beta$ was not significant. The transactivation activity of A86T-HNF-3 $\beta$ was also tested with two other reporters, HNF-1 $\alpha$-pGL3 and TTRpGL3. The transcription of HNF-1 $\alpha$ and TTR reporters by A86T-HNF-3 $\beta$ were significantly decreased compared with WT-HNF-3 $\beta$ : 83.6\% $(p=0.00037)$ and $86.2 \%(p=0.0014)$, respectively (Fig. 1$)$.

\section{Discussion}

In screening the $H N F-3 \beta$ gene in 57 Japanese subjects with late-onset Type II diabetes we found two missense mutations, A86T and G114E, and neither mutation was observed in 225 control subjects. The glycine at codon 114 is not conserved in Xenopus and Zebrafish [6]. The transactivation activity of G114E-HNF$3 \beta$ was similar to that of WT-HNF-3 $\beta$. These data suggest that the G114E mutation is not a diabetesassociated mutation. In contrast, alanine at codon 86 is conserved in human, mouse, rat, Xenopus and Zebrafish [6] and the A86T mutation was present in all (4/4) of the diabetic members of subject 1's family. The transactivation activity of A86T-HNF-3 $\beta$ was statistically significantly reduced compared with WT-HNF-3 $\beta$. The physiological importance of such a modest reduction for the ability to develop Type II 

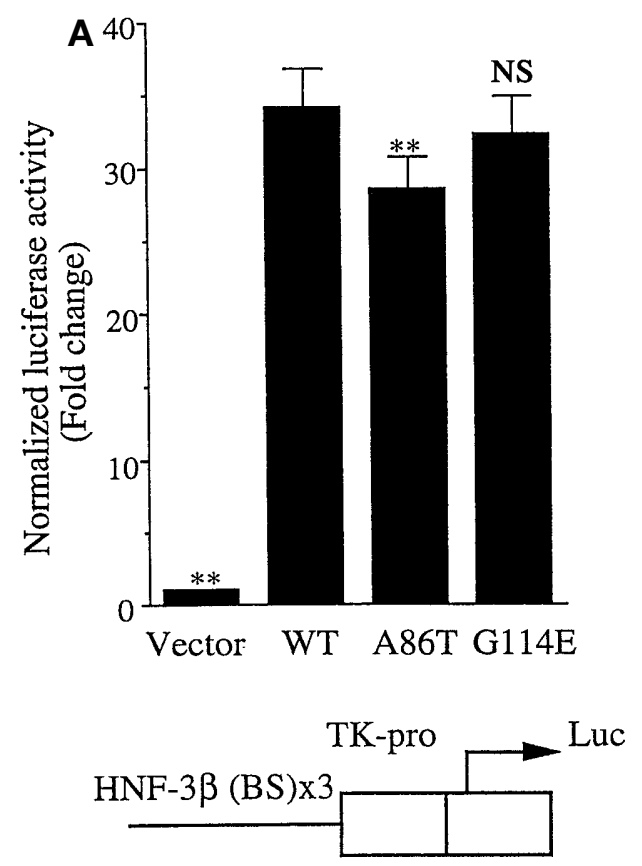

B

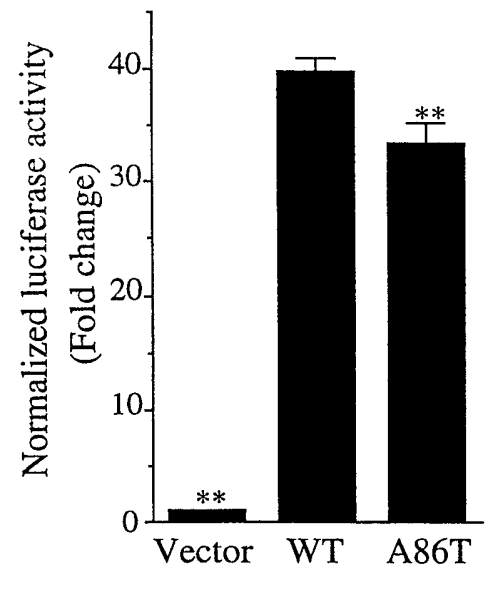

$\mathrm{HNF}-1 \alpha$

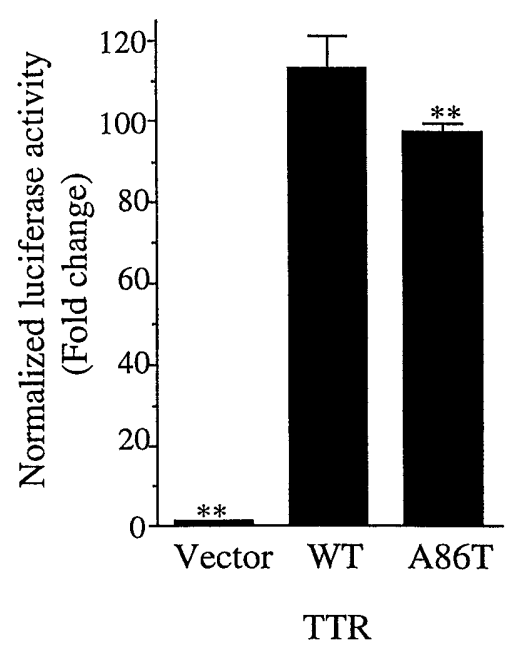

Fig. 1A, B. Transactivation activities of WT and mutant HNF$3 \beta$ in HeLa cells. Cells were transfected with $100 \mathrm{ng}$ of WT or mutant HNF- $3 \beta$ constructs and $0.5 \mu \mathrm{g}$ of the reporter genes together with $10 \mathrm{ng}$ of pRL-SV40. A pHNF3 $\beta$-tk-Luc reporter and $\mathbf{B}$ HNF-1 $\alpha$-pGL3 and TTR-pGL3. The results were from six independent experiments; means \pm SEM, $* p<0.05$, ** $p<0.01$

diabetes is not known. Recent functional studies have, however, shown that mutant HNF-1 $\alpha$ proteins with modestly impaired transactivation activity are associated with a mild form of diabetes (late onset and low penetrance) rather than MODY [8]. The late onset of diabetes observed in subjects with the A86T mutation could be a consequence of the relatively mild nature of the A86T-HNF-3 $\beta$. Alternatively, this mild mutation could be one of several polygenic factors contributing to the development of Type II diabetes.

This study indicates that mutations in the $H N F-3 \beta$ gene are not a common cause of late-onset Type II diabetes in Japanese subjects although the results apply only to the coding region of the $H N F-3 \beta$ gene. We also showed that the A86T mutation in the $H N F-3 \beta$ gene might be involved in the development of lateonset Type II diabetes in a small group of subjects in this cohort.

Acknowledgements. We thank Ms Y. Tsukahara, Dr M. Moriwaki, Dr K. Okita, Dr W. Liu and Dr M. Namba for their assistance and support. This work was supported by grants from the Japanese Ministry of Science, Education and Culture, Senri Life Science Foundation, Yamanouchi Foundation for Research on Metabolic Disorders, Uehara Memorial Foundation, Research for the Future Programme of The Japan Society for the Promotion of Science (97L00801) and Japanese Ministry of Health and Welfare (Health Science Research Grants, Research on Human Genome and Gene Therapy). K.Yamagata is a research fellow of the Japan Society for the Promotion of Science.

\section{References}

1. Yamagata K, Oda N, Kaisaki PJ et al. (1996) Mutations in the hepatocyte nuclear factor- $1 \alpha$ gene in maturity-onset diabetes of the young (MODY3). Nature 384: 455-458

2. Yamagata K, Furuta H, Oda N et al. (1996) Mutations in the hepatocyte nuclear factor- $4 \alpha$ gene in maturity-onset diabetes of the young (MODY1). Nature 384: 458-460

3. Froguel P, Velho G (1999) Molecular genetics of maturityonset diabetes of the young. Trends Endocrinol Metab. 10: 142-146

4. Duncan SA, Navas MA, Dufort D et al. (1998) Regulation of a transcription factor network required for differentiation and metabolism. Science 281: 692-695

5. Sharma S, Jhala US, Johnson T et al. (1997) Hormonal regulation of an islet-specific enhancer in the pancreatic homeobox gene STF-1. Mol Cell Biol 17: 2598-2604

6. Yamada S, Zhu Q, Aihara Yet al. (2000) Cloning of cDNA and the gene encoding human hepatocyte nuclear factor (HNF)-3 $\beta$ and mutation screening in Japanese subjects with MODY. Diabetologia 43: 121-124

7. Ghosh S, Watanabe RM, Hauser ER et al. (1999) Type 2 diabetes: Evidence for linkage on chromosome 20 in 716 Finnish affected sib pairs. Proc Natl Acad Sci USA 96: 2198-2203

8. Yang Q, Yamagata K, Yamamoto K et al. (1999) Structure/ function studies of hepatocyte nuclear factor-1alpha, a diabetes-associated transcription factor. Biochem Biophys Res Commun 266: 196-202

9. Qian X, Costa RH (1995) Analysis of hepatocyte nuclear factor- $3 \beta$ protein domains required for transcriptional activation and nuclear targeting. Nucleic Acids Res 23: 1184-1191 